\title{
The impact of neonatal abstinence syndrome: the view from a rural Kentucky hospital
}

Sydni Fazenbaker Crowell, BS ${ }^{1}$, Allison M. Crump-Rogers, MD ${ }^{1}$, William Crump, MD $^{1}$, LeAnn Langston, $\mathrm{RN}^{2}$

\section{Author Affiliations:}

1. University of Louisville School of Medicine Trover Campus at Baptist Health Madisonville, Madisonville, Kentucky

2. Health First Community Clinic, Madisonville, Kentucky

The authors have no financial disclosures to declare and no conflicts of interest to report.

\section{Corresponding Author:}

William Crump, MD

University of Louisville School of Medicine

Trover Campus at Baptist Health Madisonville

Madisonville, Kentucky

Email: bill.crump@bhsi.com 


\section{Abstract}

Introduction

Cases of neonatal abstinence syndrome (NAS) increased 3-fold in the United States from 2000 to 2009 , with some indication that the problem may be worse in rural areas. The purpose of our study was to report the incidence of NAS in a small rural community with a regional referral hospital and describe aspects of these infants' NICU stay.

\section{Methods}

Using maternal prenatal positive urine drug screens (UDS) as our initial focus, deliveries at 35 weeks or beyond between March 2015 and May 2016 were included. NAS severity score, length of NICU stay, and hospital charges for each infant were obtained from chart review.

\section{Results}

Thirty three of 981 infants developed NAS requiring NICU admission. Most of these were not identified by either a prenatal history or a routine first prenatal visit UDS. For the 7 infants who were identified as at risk by a positive UDS early in pregnancy, the average length of stay in the NICU was 10 days, the average NAS score was 8 , and the average NICU charge was $\$ 46,000$ compared to $\$ 3,440$ charge for a term normal newborn.

\section{Discussion}

Many studies have shown that neonatal abstinence syndrome is becoming more common, and some suggest that it may be a bigger problem in rural areas. While prenatal UDS may be helpful, many exposed infants will be missed. Even when exposure is proven, without reasonable access to medication assisted treatment during pregnancy, the outcome may still be unfavorable. The precise prevalence and cost in rural hospitals that serve as regional referral centers are needed for adequate health service planning. This planning includes strategies to increase local access to treatment options for pregnant women dependent on opioids.

\section{Keywords}

Neonatal Abstinence Syndrome, Rural Communities, Incidence of NAS, Substance Abuse

\section{Introduction}

Cases of neonatal abstinence syndrome (NAS) increased by 3 -fold in the United States between 2000 and 2009. ${ }^{1}$ Infants exposed in utero to drugs such as opioids, cocaine or methamphetamine are expected to develop some degree of neonatal abstinence syndrome as they undergo withdrawal abruptly after birth. Neurological, gastrointestinal, and respiratory systems are affected by neonatal abstinence syndrome and the severity of symptoms varies depending on dosage of the drug, genetic factors, adequacy of prenatal care, and gestational age of exposure. ${ }^{1}$ 
Specific signs and symptoms include irritability, high pitched crying, tremors, frequent yawning, excessive crying, seizures, poor feeding, tachypnea, and loose stools. ${ }^{1}$

In 2012, one infant born in the United States every twenty-five minutes was diagnosed with NAS. ${ }^{1}$ In 2009 an estimated $\$ 720$ million in hospital charges were attributed to NAS. ${ }^{1}$ Currently, methods used to detect fetal drug exposure include urine drug screen, meconium results, maternal hair analysis, and umbilical cord tissue toxicology.

From 2009 to 2012, the national incidence of NAS increased from 3.4 to 5.8 per 1000 live births, with significant geographic variation. The highest incidence of NAS was in the East South Central division of the United States (Kentucky, Tennessee, Mississippi, and Alabama) and in 2012 was a mean of 16.2 infants per 1000 hospital births with a range of 12.4 to 18.9. ${ }^{2}$

West Virginia reported NAS and drug-specific trends state-wide, where rurality-related issues are significant. They found that from 2007 to 2013, NAS incidence rate increased from 7.7 to 31.6 infants per 1,000 births per year. During the same time, opioid exposure increased and cocaine exposure decreased. ${ }^{3}$

The effects of drug addiction and withdrawal on mother and baby are still not completely understood. The ideal length of hospital stay for babies exposed to one or more drugs in utero is also unclear. The purpose of our study is to report the prevalence of NAS in a rural community with a regional referral hospital in an area where prenatal medication assisted treatment (MAT) for opioid dependence is not available and to describe some specific aspects of those mother/infant pairs where the prenatal urine drug screen is known to be positive.

\section{Methods}

The initial study population was all pregnant women who tested positive in a routine facility prenatal urine drug screen and delivered a viable singleton at 35 weeks or beyond between March 2015 and May 2016. During this period there were 981 deliveries at our rural facility in Kentucky that has seven labor and delivery rooms. The NICU is a 12-bed Level II, non-surgical 5,000 square foot unit. Typically, if an infant is less than twenty-eight weeks' gestation, weighs less than 1000 grams, or requires surgery, transfer will be made to a Level 3 NICU approximately 100 miles away.

Urine drug screens for common drugs of abuse were routinely done at the initial prenatal visit. The same screen was done on all admissions to labor and delivery for both laboring patients and planned cesarean sections. The same urine drug screen was done on babies whose mothers tested positive on admission. Urine was collected on infants as first void, and all meconium stool results were available 1-4 days after the specimens had been received.

The guidelines for admission to the NICU included birth weight less than 2000 grams, gestational age less than 35 weeks, infants of mothers with a history of drug use or mother that tested positive at or prior to delivery for cocaine, opiates, methadone, methamphetamines, or amphetamines. Infants were observed for signs of withdrawal for 24-72 hours or as ordered by 
the attending physician. Pharmacologic therapy initiated by the attending physician was based on Finnegan Scoring done at birth and every 3-4 hours, each within 30 minutes of feeding.

NAS was defined as any substance exposed infant that exhibited symptoms of neonatal abstinence syndrome including but not limited to tremors, hyperirritability, loose stools, vomiting, or seizures. Data including pharmacological or nonpharmacological treatment for the infants admitted to the NICU was obtained from chart review. At the initial prenatal visit, insurance coverage, demographics, gestational age at first prenatal visit, history of tobacco use, history of hepatitis $\mathrm{C}$ and selective serotonin reuptake inhibitor use were recorded, and subsequent number of prenatal visits were also obtained from chart review. None of patients in the study were receiving medication assisted treatment (MAT) for their drug use. The nearest daily administered methadone program was 2 hours away, and the nearest suboxone clinic serving prenatal patients was 1 hour away. The facility's Internal Review Board determined this study was exempt.

\section{Results}

Table 1 shows the demographics of the 58 women who had positive prenatal urine drug screens during the 15 month period, with the majority being THC alone. This is 58 of $981(6 \%)$ of all the deliveries during this time period. During this time period, $59 \%$ of all the deliveries were covered by Medicaid and $97 \%$ of these 58 women were covered by Medicaid. Table 2 shows the percentage of each drug found on the prenatal urine drug screen.

Table 1. Demographics of study subjects. N=58

\begin{tabular}{|c|c|c|}
\hline \multirow[b]{2}{*}{ Age } & Mean & Range \\
\hline & 26.81 & $16-38$ \\
\hline Number of prenatal visits & 12.7 & $5-22$ \\
\hline GA at delivery & 38.6 & $35-41.2$ \\
\hline \multirow[b]{2}{*}{ Married } & \multicolumn{2}{|c|}{$\mathrm{N}(\%)$} \\
\hline & \multicolumn{2}{|c|}{$14(24 \%)$} \\
\hline Primipara & \multicolumn{2}{|c|}{$13(22 \%)$} \\
\hline Medicaid Coverage $\mathrm{a}^{\mathrm{a}}$ & \multicolumn{2}{|c|}{$56(97 \%)$} \\
\hline Taking SSRI prenatal & \multicolumn{2}{|c|}{$13(22 \%)$} \\
\hline Taking SSRI at delivery & \multicolumn{2}{|c|}{$4(7 \%)$} \\
\hline Tobacco use & \multirow{2}{*}{\multicolumn{2}{|c|}{$43(74 \%)$}} \\
\hline Hepatitis C positive & & $6(10 \%)$ \\
\hline
\end{tabular}

${ }^{\mathrm{a}}$ Of all 981 deliveries during the same time period, 59\% had Medicaid coverage.

Table 2. Drugs reported in prenatal urine drug screens. $\mathrm{N}=58^{\mathrm{a}}$

\begin{tabular}{lc}
\hline Drug & $\mathrm{N}(\%)$ \\
\hline THC & $48(83 \%)$ \\
\hline Opioids & $10(17 \%)$ \\
\hline Amphetamine \& Methamphetamine & $9(16 \%)$ \\
\hline Benzodiazepines & $5(9 \%)$ \\
\hline Barbiturates & $1(2 \%)$
\end{tabular}

${ }^{a} 58$ patients had one or more of the drugs listed reported as present 
Focusing only on the seven women who had a prenatal positive urine drug screen and were still positive for drugs associated with NAS at delivery, Table 3 summarizes their results.

Table 3. Initial, follow-up, and delivery urine drug screen results for month. Meconium and urine drug screen for infant at delivery

\begin{tabular}{|c|c|c|c|c|c|c|}
\hline $\begin{array}{c}\text { GA at } \\
\text { initial } \\
\text { UDS } \\
\end{array}$ & $\begin{array}{c}\text { UDS result } \\
\text { at } \\
\text { initial UDS }\end{array}$ & $\begin{array}{c}\text { GA at } \\
\text { delivery }\end{array}$ & $\begin{array}{l}\text { Maternal UDS } \\
\text { result at delivery }\end{array}$ & $\begin{array}{c}\text { Infant's UDS } \\
\text { Result } \\
\end{array}$ & $\begin{array}{c}\text { Infant's } \\
\text { Meconium } \\
\text { Result } \\
\end{array}$ & $\begin{array}{c}\text { NICU } \\
\text { LoS } \\
\text { (days) } \\
\end{array}$ \\
\hline 34 & $\begin{array}{c}\text { Benzo, THC, } \\
\text { Amph }\end{array}$ & 39 & $\begin{array}{l}\text { Amph, THC, } \\
\text { Opiates }\end{array}$ & Neg & $\begin{array}{c}\text { Amphet, } \\
\text { Opiates, } \\
\text { THC }\end{array}$ & 5 \\
\hline 36 & Benzo & 39 & Oxy & Oxy & $\begin{array}{c}\text { THC, } \\
\text { Opiates }\end{array}$ & 30 \\
\hline 11 & $\begin{array}{c}\text { THC, Barbs, } \\
\text { Opiates }\end{array}$ & 39 & $\begin{array}{c}\text { THC, Opiates, } \\
\text { Oxy }\end{array}$ & THC, Opiates & $\begin{array}{l}\text { Same as } \\
\text { UDS }\end{array}$ & 9 \\
\hline 10 & THC, Oxy & 39 & Opiates, Oxy & Opiates, THC & $\begin{array}{l}\text { Same as } \\
\text { UDS }\end{array}$ & 11 \\
\hline 12 & THC, Benzo & 40 & $\begin{array}{c}\text { Benzo, Amph, } \\
\text { Oxy }\end{array}$ & $\begin{array}{c}\text { Benzo, Amph, } \\
\text { Oxy, THC, } \\
\text { Opiates, } \\
\text { buprenorphine }\end{array}$ & $\begin{array}{l}\text { Same as } \\
\text { UDS }\end{array}$ & 25 \\
\hline 11 & $\begin{array}{l}\text { Amph, } \\
\text { Opiates }\end{array}$ & 37 & Amph, Opiates & $\begin{array}{l}\text { Amph, } \\
\text { Opiates }\end{array}$ & $\begin{array}{c}\text { Same as } \\
\text { UDS }\end{array}$ & 4 \\
\hline 11 & Opiates & 37 & Oxy & Opiates & $\begin{array}{c}\text { Same as } \\
\text { UDS }\end{array}$ & 9 \\
\hline
\end{tabular}

The average length of stay in the NICU for these seven infants was 10 days with range of 4-30 days. The average NAS score was 8 with a range of 0-16. Five required pharmacological treatment, with four prescribed morphine and one both morphine and clonidine. All seven babies tested positive in meconium results. The total charge for these 7 babies was $\$ 322,000$. The average charge for the hospital portion for a term, well infant during the study period was $\$ 3,144$.

During this same time-period, an additional 40 infants met NICU admission criteria for potential NAS, and 26 were diagnosed with some level of NAS. These mothers did not have a documented positive prenatal history of drug use or a positive urine prenatal drug screen.

\section{Discussion}

The opioid epidemic has brought into sharp focus the use of opioids by women of childbearing age and the possibility of resultant neonatal abstinence syndrome. Some studies suggest that the majority of the increase in NAS can be attributed to the rise in opioid prescriptions rather than acquisition without a prescription, but undoubtedly both occur. ${ }^{4,5}$ Rural communities may face an even larger challenge with NAS due to inadequate treatment resources. Pregnant women living 
in rural towns may need to commute long distances to find a treatment facility serving pregnant women who accept their form of payment. The issue is heightened when the woman has other children and responsibilities that she cannot leave to seek treatment far away. This could result in a woman either continuing opioid use or trying withdrawal on her own, both of which could be harmful to her fetus. ${ }^{3,4}$

The health risks associated with substance use disorder include increased prevalence of hepatitis $\mathrm{C}$ and human immunodeficiency virus (HIV) from sharing needles, bacterial infections from injecting or skin popping, and sexually transmitted infections from trading sex for drugs or other high-risk sexual behavior. ${ }^{4}$ Our data supports this association, with 6 women (10\%) testing positive for hepatitis $\mathrm{C}$. This population of women lack healthy coping mechanisms due to a multitude of factors such as unstable homes, unhealthy habits such as smoking and drug use, inadequate support, and high levels of stress. ${ }^{4}$

In 2013, Tennessee implemented an online surveillance system for NAS that requires the hospital to report a new NAS diagnosis within 30 days. ${ }^{7}$ With this online reporting system, they found a higher NAS case rate in the rural Appalachian counties of eastern Tennessee than in more urban and suburban areas. ${ }^{7}$ By including geographic demographics such as women's county of residence and source of exposure, targeted interventions can be developed to best address local needs. ${ }^{7}$ CDC also found that in the United States, higher rates of opioid prescriptions were found among women of reproductive age in the South. ${ }^{8}$ In this same CDC study, opioid prescription rates were higher among women enrolled in Medicaid. ${ }^{8}$ Rural patients typically are covered by Medicaid more than in more suburban environments.

Studies show that if pregnant women choose an inpatient detoxification program and are successful, the infants of these women have shorter hospitalizations, lower NAS scores, and are less likely to be treated for withdrawal. ${ }^{5}$ Maternal-newborn contact, rooming-in, and breastfeeding may help to decrease the severity of NAS and the need for pharmacological treatment of NAS. ${ }^{5,6}$

In our study of one rural hospital over a 15 month period, we found that our incidence of symptomatic NAS infants was 33 per thousand. Most of these infants were not identified during a prenatal history or prenatal urine drug screen. This is not uncommon, as women using illicit drugs may not report this, and with the dilute urine of pregnancy, false negative urine drug screens are probably frequent.

The cost of the seven term infants that were identified in advance demonstrates the severity of these situations. For these 7 infants the average length of stay in the NICU was 10 days with an average charge of $\$ 46,000$ per infant. The one pre-term NAS infant excluded from this analysis alone had \$110,000 in charges and a 24 day stay. Born at 34 weeks, the NAS aspect almost surely contributed to both length of stay and therefore charges. It is important to note the inability to change the course of these 7 term NAS infants, despite knowing that the mother's initial prenatal urine drug screen was positive. Careful prenatal care with appropriate urine drug screening still misses mothers who are using something other than THC and even if positive, if there is no local access to treatment, changing the outcome is difficult. This prolonged length of stay in the NICU for all 8 infants was in a population where none of the women were in a 
medication assisted treatment program (MAT). The lack of MAT treatment availability near many rural communities creates a significant gap in medical care for pregnant women using drugs, at a considerable cost.

Limitations of our study include lack of generalizability, as we report one small group at one rural hospital. Rural communities like ours may find value in our results and are encouraged to replicate them. The data was obtained by chart review performed by a highly experienced perinatal nurse, but with any manual chart review, limitations include transcription errors and missing data. We limited our data set to those variables for which we had complete data, and even then the review was very labor intensive. Because of our focus on differentiating the NICU course in term NAS infants, 2 infants delivered at 34 weeks' gestation were excluded. One of these born at 34 weeks had charges of $\$ 110,000$, and a significant amount of that cost was probably secondary to NAS. Our study is strengthened because $99 \%$ of patients who delivered at our facility were taken care of by one group of providers including certified nurse midwifes and physicians, and prenatal drug screening had become routine, and any tests missed were completed by ongoing quality assurance processes. This allows us to demonstrate that prenatal urine drug screens miss some patients needing attention.

In conclusion, we found that 33 infants per 1000 deliveries at our rural hospital required NICU admission for NAS, at significant cost. Our prevalence was higher than in most older reports, but in line with recent reports from West Virginia. The increasing prevalence of NAS in rural communities has created a need for wider availability of prenatal MAT and perhaps an opportunity for medical professionals and policy makers to focus on targeted treatment methods to reduce opioid dependence and addiction among women of child bearing age, ideally before pregnancy is established. Increasing access to maintenance and prevention treatment for pregnant mothers in rural communities would prove beneficial to reduce cost in the long run by avoiding NICU admissions and extended NAS pharmacologic and nonpharmacologic treatment. Reducing NAS occurrence is an important goal in maternal and child health and future studies should track the prevalence and costs as attempts at prevention using both supervised abstinence and MAT maintenance programs are implemented. 


\section{References}

1. Patrick SW, Davis MM, Lehmann CU, Cooper WO. Increasing incidence and geographic distribution of neonatal abstinence syndrome: United States 2009 to 2012. Journal of Perinatology. 2015 35(8), 650-655. doi: 10.1038/jp.2015.36. Erratum in: Journal of Perinatology. 2015 35(8):667. Lehman, C U [corrected to Lehmann, C U].

2. Patrick SW, Schumacher RE, Benneyworth BD, Krans EE, McAllister JM, Davis MM. Neonatal abstinence syndrome and associated health care expenditures: United States, 2000-2009. Journal of the American Medical Association. 2012 307(18):1934-1940. doi: 10.1001/jama.2012.3951.

3. Stabler ME, Long DL, Chertok IR, Giacobbi PR Jr., Pilkerton C, Lander LR. (2016). Neonatal Abstinence Syndrome in West Virginia substate regions, 2007-2013. Journal of Rural Health. 2017 33(1):92-101. doi: 10.1111/jrh.12174.

4. Kremer ME, Arora KS. Clinical, ethical, and legal considerations in pregnant women with opioid abuse. Obstetrics \& Gynecology. 2015 126(3);474-478. doi: 10.1097/AOG.0000000000000991.

5. Kaltenbach K, Jones HE. Neonatal Abstinence Syndrome: presentation and treatment considerations. Journal of Addiction Medicine. 2016 10(4);217-223. doi: 10.1097/ADM.0000000000000207.

6. Ordean A, Kahan M, Graves L, Abrahams R, Kim T. Obstetrical and neonatal outcomes of methadonemaintained pregnant women: a Canadian multisite cohort study. Journal of Obstetrics and Gynaecology Canada. 2015 37(3):252-257.

7. Warren MD, Miller AM, Traylor J, Bauer A, Patrick SW. Centers for Disease Control and Prevention (CDC). Implementation of a statewide surveillance system for neonatal abstinence syndrome - Tennessee, 2013. Morbidity and Mortality Weekly Report. 2015 64(5):125-128.

8. $\quad$ Ailes EC, Dawson AL, Lind JN, Gilboa SM, Frey MT, Broussard CS, et al. Centers for Disease Control and Prevention (CDC). Opioid prescription claims among women of reproductive age--United States, 2008-2012. Morbidity and Mortality Weekly Report. 2015 64(2):37-41. 